\title{
Regulatory Impact Assessment Role in Developing Participatory Work between Civil Society Organizations and Jordanian Ministry of Political and Parliamentary Affairs
}

\author{
Dr. Amani G. Jarrar ${ }^{1}$ \\ ${ }^{1}$ Department of Development Studies, Faculty of Arts, Philadelphia University, Jordan \\ Correspondence: Dr. Amani G. Jarrar, Department of Development Studies, Faculty of Arts, Philadelphia \\ University, Jordan. Tel: 009-627-9552-2401. E-mail: aj8infinity@gmail.com
}

Received: December 4, 2017 Accepted: February 10, 2018 Online Published: February 25, 2018

doi:10.5539/jpl.v11n1p88

URL: https://doi.org/10.5539/jpl.v11n1p88

\begin{abstract}
The study points out the role of regulatory assessment in developing participatory work in Jordan focusing on both civil society organizations and Ministry of Political \& Parliamentary Affairs. Jordan, nowadays ,has a rapidly evolving policy and regulatory environment. The problem that is rooted in our societies and national institutions manifests in the absence or lack of coordination in order to achieve the desired results that are planned to reach, namely the efficiency and effectiveness of the institutional performance of all sectors, especially the development sectors. The study poses the questions dealing with empowering a decentralized RIA System in Jordan, mainly: Determining the policies to be achieved to solve the problem, identifying the problems to be treated, determining the appropriate option for policy enforcement, determining the type of legislation required, determining who is responsible for preparing these legislations, and identifying the necessary legal and administrative mechanisms required. The research used the descriptive analytical, methodology. The study proposes an institutional mechanism of the (RIA) in Jordan.
\end{abstract}

Keywords: regulatory impact assessment (RIA), participatory work, civil society organizations, political and parliamentary affairs, Jordan

\section{Introduction}

Jordan has a rapidly evolving policy and regulatory environment. More than 1,000 legal acts (laws, parliament resolutions, and government resolutions) are adopted every year. Public participation is a central requirement for good governance, not just in light of the fact that it offers voice to the general population for issues that influence them and choices that are made in their name, additionally on the grounds that it adds to amplifying the quality and viability of policy-making. Engagement of nationals in approach making brings open trust up in establishments and their choices by giving general society a feeling of proprietorship. The expectation to connect with nationals in basic leadership should be true in light of the fact that the entire procedure is futile unless proposals and suggestions are to be considered and people in general persuaded that they can make an impact. On the opposite, it might even have unfriendly impacts by bringing down open trust in organizations. (Skopje, 2015).

Many civil society organizations (CSOs) in Jordan have made a positive impact by working side-by-side with the government institutions in improving public engagement in policy-making, as well as criticizing them, about why and how institutions need to conduct their consultations with CSOs and citizens. Participatory policies are the most profound basis for the creation of an enabling environment for CSOs (Carothers \& Ottaway, 2010).

The legislative premise that controls the work of government organizations and additionally key reports received by the administration demonstrate a dedication and thought for engagement of civil society in policy-making.

The Government of Jordan, led by the ministry of political and parliamentary affairs is setting up by 2017 a Regulatory Impact Assessment (RIA) policy and management system (RIA System) for newly proposed legal acts. Suggesting a proposed decentralized RIA System for Jordan , where most responsibilities for ensuring good RIA are delegated to regulators with the support of a central body (Barreto, Cordova \& Gutan, 2015). 


\section{Problem Statement and Questions of the Study}

The existence of a participatory relationship between the State and civil society organizations is a necessity dictated by the real interdependence of geography and politics, both of which operate within a single geographical area and political considerations that make both seek a better society, the society of justice, equality and the rule of law. They are rich in each other because of the interests, and goals they share, which are common denominators that lead to dialogue and participation rather than conflict. It is in the interest of the Jordanian state and civil society to establish strong and institutionalized participatory relationships. The need to meet the state and civil society in one way to establish a more participative, complementary and mutually trusting relationship is particularly urgent.

Policy promoting cooperation between the state (public authorities: government and parliament) and civil society organizations (CSOs) are important not only because they support collaboration on jointly identified themes, but can also be tool of confidence and trust building. Therefore this study is trying to answer the study question: what is the role of Regulatory Impact Assessment (RIA) with its seven steps in developing participatory work between Civil Society Organizations and Ministry of Political and Parliamentary Affairs in Jordan?

\section{Importance of the Study}

The importance of this study is shown in its response to the limits of the relationship between the joint work of the Ministry of Political and Parliamentary Affairs in Jordan and civil society organizations through the regulatory impact assessment processes.

\section{Objectives of the Study}

Legislative reforms are essential to the creation of a social and political consensus that seeks to make progress in the area of comprehensive reform in various areas. It begins with the process of building and shaping policy, and establishing the joint efforts between the Ministry of Political and Parliamentary Affairs in Jordan and civil society organizations through the regulatory impact assessment processes for:

- Determining the policies to be achieved to solve the problem

- Identifying the problem for treatment

- Determining the appropriate option for policy enforcement

- Determining the type of legislation required (new law, regulation, instructions, legislative amendment)

- Determining who is responsible for preparing these legislations

\section{Study Methodology}

The research used the descriptive, analytical, and practical methodology.

On the descriptive side, the methodology was to describe the Jordanian political system, legislation, the Jordanian legislative system and parliament, the mechanism for formulating public policies, as well as the study of Jordanian civil society organizations, and the evaluation of parliamentary policies. For this purpose, a structured methodology has been adopted based on the logical construction of concepts, perhaps the most important of which is the concept of regulatory impact assessment (RIA).

\section{Study Model}

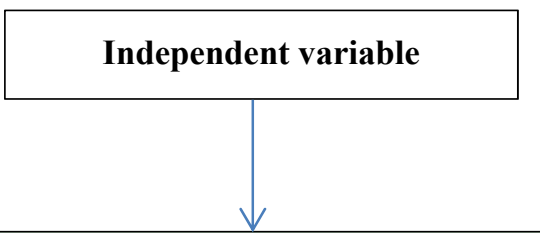

Regulatory Impact Assessment (RIA)

Defining the problem

Setting goals

Selecting options

Measuring effects

Application and compliance

Monitoring and evaluation

Consultation

\section{Participatory Work}




\section{Study Hypotheses}

\subsection{Major Hypothesis}

H0: There will be no statistically significant differences at the level of significance $(\alpha=0.05)$ of the role of regulatory impact assessment (RIA) on the participatory work between Civil Society Organizations and Ministry of Political and Parliamentary Affairs in Jordan.

\subsection{Sub-hypotheses}

H01: There will be no statistically significant differences at the level of significance $(\alpha=0.05)$ of the role of defining the problem on the participatory work between Civil Society Organizations and Ministry of Political and Parliamentary Affairs in Jordan.

H02: There will be no statistically significant differences at the level of significance $(\alpha=0.05)$ of the role of setting goals on the participatory work between Civil Society Organizations and Ministry of Political and Parliamentary Affairs in Jordan.

H03: There will be no statistically significant differences at the level of significance $(\alpha=0.05)$ of the role of selecting options on the participatory work between Civil Society Organizations and Ministry of Political and Parliamentary Affairs in Jordan.

H04: There will be no statistically significant differences at the level of significance $(\alpha=0.05)$ of the role of measuring effects on the participatory work between Civil Society Organizations and Ministry of Political and Parliamentary Affairs in Jordan.

H05: There will be no statistically significant differences at the level of significance $(\alpha=0.05)$ of the role of application and compliance on the participatory work between Civil Society Organizations and Ministry of Political and Parliamentary Affairs in Jordan.

H06: There will be no statistically significant differences at the level of significance $(\alpha=0.05)$ of the role of monitoring and evaluation on the participatory work between Civil Society Organizations and Ministry of Political and Parliamentary Affairs in Jordan.

H07: There will be no statistically significant differences at the level of significance $(\alpha=0.05)$ of the role of consultation on the participatory work between Civil Society Organizations and Ministry of Political and Parliamentary Affairs in Jordan.

\section{Literature Review}

The political system in Jordan is based on the Constitution of 1952 on three pillars: the executive authority, represented by the king as head of state, the cabinet, and the legislative authority, represented by the National Assembly consisting of the Houses of Deputies and the Judiciary and represented by courts of various types and specialties. The executive authority in the Hashemite Kingdom of Jordan has two main pillars: The king, the head of state, the prime minister and his ministerial team.

\subsection{Legislative System in the Jordanian Parliament}

The draft laws shall be forwarded by the Government to the Council of Representatives by an official letter from the Prime Minister, accompanied by the reasons for it, as approved by the Council of Ministers, requesting the referral of it to the House of Representatives for approval. After the law is submitted to the Chamber of Deputies. The project may be referred to the competent committee, which in turn studies the law in detail, and may summon the competent minister or his deputy, senior officials or those who believe it is necessary to hear the opinion of the concerned parties and experts (Aladwan \& Aldab, 2015).

\subsection{Civil Society Organizations in Jordan}

Civil society organizations (CSOs) are a group of free voluntary organizations that fill the public sphere between the family and the state. They are established to achieve the interests of their members or to provide services to citizens or to carry out a variety of humanitarian activities and to abide by values and standards of respect, compromise, tolerance, participation and peaceful management of diversity and difference.

King Abdullah II era has witnessed the process of political and economic openness and globalization, Jordan's entry into several international economic agreements and the strengthening of relations with international institutions, which contributed to the creation of an internal and external environment supportive of civil society, and the need to involve civil society in the management of state affairs, and there were clear provisions in those conventions referring to this (Yom, 2005). 


\subsection{Intersections of Jordanian Legislation with Civil Society Organizations}

The follower of the civil society relations in Jordan, believes that it has undergone many fluctuations and forms, and the relationship is affected by the current political situation and the changes and transformations dictated by external and internal factors. In 1989, Jordan witnessed a historic shift in the abolition of martial law, the restoration of parliamentary life and the entry into a stage of political openness, which contributed to the reconsideration of the presence of civil society. The opposition of political parties have regained their legitimacy and have been re-registered following the enactment of a law regulating their work (Misztal, 2013).

\subsection{Regulatory Impact Assessment (RIA)}

The Regulatory Impact Assessment (RIA) is the process of identifying and evaluating the expected effects of regulatory proposals, using a consistent analytical approach, such as benefit / cost analysis, which is based on defining basic organizational objectives and identifying all policy interventions that can be achieved in advance of feasible alternatives. Possible options should also be assessed, using the same method, to inform decision-makers about the effectiveness and efficiency of different options, thus selecting the most effective and efficient options (Adelle, Macrae, Marusic \& Naru, 2015).

\subsection{Regulatory Impact Assessment (RIA) and (CSOs)}

Regulations are main instruments for policy making in any nation, influencing a wide range of different groups in the society in an unexpected way. Conducting RIA will help to ensure that all the parties have a good understanding of who will be affected by the proposed model of social participation. This will allow identifying winners and losers, and defining a communication strategy that will ensure collaboration and eventually success in implementation of the proposed policy model. RIA is considered an appropriate regulation tool used to make the proposed public policy model more effective and its implementation more efficient, by enhancing the public value of the decision to introduce social participation in any country (Kasamets, 2001).

\section{Study Tool}

\subsection{Questionnaire}

The study relied mainly on the questionnaire designed and prepared by the researcher.

After examining the literature and theoretical studies relevant to the subject of this study; whether in periodicals, books or other references, the questionnaire was formed in three parts and as follows:

Part I: It includes information relating to the respondents and their organisations.

Part II: It includes (35) paragraph related to the measurement of role of Regulatory Impact Assessment (RIA) with its seven steps in developing.

These seven steps have been identified as the developing techniques supporting participatory work between Civil Society Organizations and Ministry of Political and Parliamentary Affairs in Jordan; as follows:

- $\quad$ Defining the problem (1-5),

- $\quad$ Setting goals (6-10),

- $\quad$ Selecting options (11-15),

- $\quad$ Measuring effects (16-20),

- $\quad$ Application and compliance (21-25),

- $\quad$ Monitoring and evaluation (26-30),

- $\quad$ Consultation (31-35).

Part III: It includes (7) (36-42) paragraphs measuring the participatory work between Civil Society Organizations and Ministry of Political and Parliamentary Affairs in Jordan.

\subsection{Validity and Reliability Test}

Questionnaire was subjected to the validity and the reliability test, in order to emphasise the capacity of the paragraphs and then to measure what it was developed for, The questionnaire also have been subjected to the reliability test aiming to ensure the same results if it was re-applied to respondents again.

\subsubsection{Questionnaire Validity}

Ensuring the validity of the measurement tool was the aim; the questionnaire was reviewed by a number of faculty members of the Jordanian universities in the same field of the research, for identifying the suitability of the questionnaire for the goals to be achieved, and by retrieving all suggestions, all the necessary adjustments on 
the paragraphs of the questionnaires were made, by deleting, adding some paragraphs, and by rephrasing others.

\subsubsection{Questionnaire Reliability}

For ensuring the reliability of the questionnaire, the researcher used the internal consistency coefficient $(\alpha)$ according to the alpha Cronbach equation, and the value of $(\alpha) 97 \%$, which is very high when compared with the minimum acceptable of $60 \%$. The reliability of the study tool was tested by applying a sample of twenty employees, then reapplying after (15) days on the same sample, by which the Pearson correlation coefficient were extracted showing a result of (0.921); indicating a high degree of reliability.

These employees were excluded from the distribution of the questionnaires later.

\section{Study Analysis and Results}

This section aims at displaying and analysing the arithmetic means and the standard deviations of the respondents' answers concerning the questionnaire paragraphs, then testing the respondents' point of view regarding the questionnaire ,consisting of (40) paragraphs. In order to compare the arithmetic means of the responses according to the scale of the questionnaire, adopting the five-point Likert scale.

\subsection{Trends toward the Regulatory Impact Assessment Steps}

\subsubsection{Defining the Problem}

Defining the problem variable is measured in paragraphs (1-5), as illustrated in table (1), and the arithmetical means for answers of the study sample measure the problem variable ranging between $(3.69-2.52)$, and the standard deviations ranging between (0.703-0.813).

All of these arithmetic means show the approval of the study sample on the paragraphs that measure the defining of the problem variable, since all the arithmetic means are greater than the default means.

It is also noted that the paragraph, which states "Defining of the problem means identification of target groups and distribution of impacts" had the highest approval grades; as its arithmetic means was (3.69) and its standard deviation was (0.803), while the paragraph, which states "We should clarify why the problem is not resolved by the existing legislative frameworks" had the lowest approval grades; as its arithmetic means was (2.52) and its standard deviation was $(0.762)$.

Overall, the general average of the arithmetic means for the answers of the respondents is equivalent to (3.18) and the standard deviation is equivalent to (0.768), which indicates the approval of the respondents on the scale of these paragraphs was medium, and that their attitudes were positive.

Table1. Arithmetic means and standard deviations for the members of the study sample answers towards the defining of the problem

\begin{tabular}{clcccc}
\hline NO & \multicolumn{1}{c}{ Statement } & A M & S D & Rank & Grade \\
\hline 1 & $\begin{array}{l}\text { The first step of defining the problem is the determination } \\
\text { of the size of the problem }\end{array}$ & 2.91 & 0.758 & 4 & Medium \\
2 & $\begin{array}{l}\text { The process of identifying causes is necessary to define the } \\
\text { problem }\end{array}$ & 3.22 & 0.813 & 3 & Medium \\
3 & $\begin{array}{l}\text { Defining of the problem means identification of target } \\
\text { groups and distribution of impacts }\end{array}$ & 3.69 & 0.803 & 1 & High \\
4 & $\begin{array}{l}\text { We should determine whether the problem is in the absence } \\
\text { of legislation } \\
5\end{array}$ & 3.58 & 0.703 & 2 & Medium \\
existing legislative frameworks & General average & 3.18 & 0.768 & - & Medium \\
\hline
\end{tabular}

\subsubsection{Setting Goals}

The setting goals variable is measured in paragraphs (6-10), as illustrated in table (2), and the arithmetical means for answers of the study sample that measure the setting goals variable ranged between $(3.88-2.78)$, and the standard deviations ranged between (0.811-0.735).

All of these arithmetic means show the approval of the study sample on the paragraphs that measure the setting goals variable, since all the arithmetic means are greater than the default mean. 
Also noted that the paragraph, which states "The clear presentation of objectives allows better oversight of the implementation and evaluation of these objectives" as its arithmetic mean was (3.88) and its standard deviation was $(0.735)$, while the paragraph, which states "The number of goals should be limited, and the prioritization should be clearly defined" had the lowest approval grades; as its arithmetic means was (2.78) and its standard deviation was (0.802).

Overall, the general average of the arithmetic means for the answers of the respondents is equivalent to (3.36) and the standard deviation is equivalent to $(0.783)$, which indicates the approval of the respondents upon the scale of these paragraphs was medium, and that their attitudes were positive.

Table 2. Arithmetic means and standard deviations for the members of the study sample answers towards the setting goals variable

\begin{tabular}{clccccc}
\hline NO & \multicolumn{1}{c}{ Statement } & A M & S D & Rank & Grade \\
\hline 6 & $\begin{array}{l}\text { Formulation of objectives, results and regulatory measures } \\
\text { to correspond to problems, causes and effects } \\
\text { The number of goals should be limited, and the } \\
\text { prioritization should be clearly defined } \\
\text { Ensuring that the objectives are consistent with government } \\
\text { strategies and programs }\end{array}$ & 3.69 & 0.811 & 2 & High \\
9 & $\begin{array}{l}\text { The clear presentation of objectives allows better oversight } \\
\text { of the implementation and evaluation of these objectives }\end{array}$ & 3.88 & 0.802 & 5 & Medium \\
10 & Goals are the outcomes and criteria that will fix problems & 3.45 & 0.791 & 4 & Medium \\
\hline General average & 3.36 & 0.783 & -1 & High \\
\hline
\end{tabular}

\subsubsection{Selecting Options}

The selecting options variable is measured in paragraphs (11-15), as illustrated in table (3), and the arithmetical means for answers of the study sample that measure the selecting options variable ranged between $(3.87$ - 2.88), and the standard deviations ranged between (0.811-0.778).

All of these arithmetic means show the approval of the study sample on the paragraphs that measure the selecting options variable, since all the arithmetic means are greater than the default mean.

It is also noted that the paragraph, which states "Defining policy options to achieve objectives must ensure that these options are relevant, practical, and preferred" as its arithmetic means was (3.87), and its standard deviation was (0.809), while the paragraph, which states "Regulatory and non-regulatory options should be considered" had the lowest approval grades; as its arithmetic means was (2.88), and its standard deviation was (0.781).

Overall, the general average of the arithmetic means for the answers of the respondents is equivalent to (3.25) and the standard deviation is equivalent to (0.794), which indicates the approval of the respondents upon the scale of these paragraphs was medium, and that their attitudes were positive.

Table 3. Arithmetic means and standard deviations for the members of the study sample answers towards the selecting options variable

\begin{tabular}{clcccc}
\hline NO & \multicolumn{1}{c}{ Statement } & A M & S D & Rank & Grade \\
\hline 11 & $\begin{array}{l}\text { Before selecting preferred options, all possible spectrum } \\
\text { options must be developed }\end{array}$ & 3.01 & 0.778 & 4 & Medium \\
12 & $\begin{array}{l}\text { Defining policy options to achieve objectives must ensure } \\
\text { that these options are relevant, practical, and preferred }\end{array}$ & 3.87 & 0.809 & 1 & High \\
13 & $\begin{array}{l}\text { The option of keeping the status quo could be the best } \\
\text { option }\end{array}$ & 3.12 & 0.793 & 3 & Medium \\
14 & $\begin{array}{l}\text { Regulatory and non-regulatory options should be } \\
\text { considered }\end{array}$ & 2.88 & 0.781 & 5 & Medium \\
15 & $\begin{array}{l}\text { Narrow the number of options by detecting constraints for } \\
\text { each option and agreeing with predefined criteria }\end{array}$ & 3.39 & 0.811 & 2 & Medium \\
\hline & General average & 3.25 & 0.794 & - & Medium \\
\hline
\end{tabular}




\subsubsection{Measuring Effects}

The measuring effects variable is measured in paragraphs (16-20), as illustrated in table (4), and that the arithmetical means for answers of the study sample that measure the measuring effects variable ranged between (3.96-2.87), and the standard deviations ranged between (0.844- 0.762).

All of these arithmetic means show the approval of the study sample on the paragraphs that measure the measuring effects variable, since all the arithmetic means are greater than the default mean.

It is also noted that the paragraph, which states "We should determine the potential economic, social and environmental impacts of each option" as its arithmetic means was (3.96) and its standard deviation was (0.762), while the paragraph, which states "Consider the risks of implementation and obstacles to optimal application" had the lowest approval grades; as its arithmetic means was (2.87) and its standard deviation was (0.844).

Overall, the general average of the arithmetic mean for the answers of the respondents is equivalent to (3.50) and the standard deviation is equivalent to (0.801), which indicates the approval of the respondents upon the scale of these paragraphs was medium, and that their attitudes were positive.

Table 4. Arithmetic means and standard deviations for the members of the study sample answers towards the measuring effects variable

\begin{tabular}{|c|c|c|c|c|c|}
\hline NO & Statement & $\mathbf{A M}$ & S D & Rank & Grade \\
\hline 16 & Relevant quantitative analytical methods should be applied & 3.51 & 0.789 & 3 & Medium \\
\hline 17 & $\begin{array}{l}\text { Consider the risks of implementation and obstacles to } \\
\text { optimal application }\end{array}$ & 2.87 & 0.844 & 5 & Medium \\
\hline 18 & $\begin{array}{l}\text { We should identify which social groups or sectors are most } \\
\text { affected by the options }\end{array}$ & 3.72 & 0.791 & 2 & High \\
\hline 19 & $\begin{array}{l}\text { We should develop a list of direct and indirect positive and } \\
\text { negative effects }\end{array}$ & 3.43 & 0.843 & 4 & Medium \\
\hline 20 & $\begin{array}{l}\text { We should determine the potential economic, social and } \\
\text { environmental impacts of each option }\end{array}$ & 3.96 & 0.762 & 1 & High \\
\hline & General average & 3.50 & 0.801 & - & Medium \\
\hline
\end{tabular}

\subsubsection{Application and Compliance}

The application and compliance variable is measured in paragraphs (21-25), as illustrated in table (5), and the arithmetical means for answers of the study sample that measure the application and compliance variable ranged between (3.96-2.87), and the standard deviations ranged between (0.844- 0.762).

All of these arithmetic means show the approval of the study sample on the paragraphs that measure the application and compliance variable, since all the arithmetic means are greater than the default means.

It is also noted that the paragraph, which states "This step includes the determination of the positive or negative effects for each option" as its arithmetic means was (3.96) and its standard deviation was (0.788), while the paragraph, which states "Option selection versus government strategies and priorities" had the lowest approval grades; as its arithmetic means was (2.43) and its standard deviation was (0.867).

Overall, the general average of the arithmetic means for the answers of the respondents is equivalent to (3.09) and the standard deviation is equivalent to (0.806), which indicates the approval of the respondents upon the scale of these paragraphs was medium, and that their attitudes were positive. 
Table 5. Arithmetic means and standard deviations for the members of the study sample answers towards the application and compliance variable

\begin{tabular}{|c|c|c|c|c|c|}
\hline NO & Statement & A M & S D & Rank & Grade \\
\hline 21 & $\begin{array}{l}\text { Highlighting the processes associated with each option is a } \\
\text { must }\end{array}$ & 2.55 & 0.839 & 4 & Medium \\
\hline 22 & Results should be grouped and categorized by each option & 3.56 & 0.746 & 2 & Medium \\
\hline 23 & $\begin{array}{l}\text { This step includes the determination of the positive or } \\
\text { negative effects for each option }\end{array}$ & 3.69 & 0.788 & 1 & High \\
\hline 24 & Option selection versus government strategies and priorities & 2.43 & 0.867 & 5 & Medium \\
\hline \multirow[t]{2}{*}{24} & $\begin{array}{l}\text { If possible, arrange options in terms of different evaluation } \\
\text { criteria }\end{array}$ & 3.22 & 0.792 & 3 & Medium \\
\hline & General average & 3.09 & 0.806 & - & Medium \\
\hline
\end{tabular}

\subsubsection{Monitoring and Evaluation}

The monitoring and evaluation variable is measured in paragraphs (26-30), as illustrated in table (6), and that the arithmetical means for answers of the study sample that measure the monitoring and evaluation variable ranged between (3.87-3.01), and the standard deviations ranged between (0.843-0.768).

All of these arithmetic means show the approval of the study sample on the paragraphs that measure the monitoring and evaluation variable, since all the arithmetic means are greater than the default mean.

It is also noted that the paragraph, which states "There must be a way to determine whether the regulatory changes have been completed efficiently" as its arithmetic means was (3.87), and its standard deviation was (0.771), while the paragraph, which states "Plans should also be made on how and when legislation will be reviewed" had the lowest approval grades; as its arithmetic means was (3.01) and its standard deviation was (0.843).

Overall, the general average of the arithmetic means for the answers of the respondents is equivalent to (3.50) and the standard deviation is equivalent to (0.794), which indicates the approval of the respondents upon the scale of these paragraphs was medium, and that their attitudes were positive.

Table 6. Arithmetic means and standard deviations for the members of the study sample answers towards the monitoring and evaluation variable

\begin{tabular}{clcccc}
\hline NO & \multicolumn{1}{c}{ Statement } & A M & S D & Rank & Grade \\
\hline 26 & $\begin{array}{l}\text { The stakeholders should undertake periodic review of } \\
\text { legislative interventions }\end{array}$ & 3.71 & 0.768 & 2 & High \\
27 & $\begin{array}{l}\text { Plans should also be made on how and when legislation will } \\
\text { be reviewed }\end{array}$ & 3.01 & 0.843 & 5 & Medium \\
28 & $\begin{array}{l}\text { There must be a way to determine that the preferred option } \\
\text { was more useful than other alternatives }\end{array}$ & 3.59 & 0.789 & 3 & Medium \\
29 & $\begin{array}{l}\text { There must be a way to determine whether the regulatory } \\
\text { changes have been completed efficiently } \\
\text { Determine whether a new intervention is still required, or } \\
\text { whether the current intervention is still appropriate }\end{array}$ & 3.87 & 0.771 & 1 & High \\
$\quad$ General average & 3.50 & 0.794 & - & Medium \\
\hline
\end{tabular}

\subsubsection{Consultation}

The consultation variable is measured in paragraphs (31-35), as illustrated in table (7), and the arithmetical means for answers of the study sample that measure the consultation variable ranged between (3.88- 3.13), and the standard deviations ranged between $(0.821-0.743)$.

All of these arithmetic means show the approval of the study sample on the paragraphs that measure the consultation variable, since all the arithmetic means are greater than the default mean.

It is also noted that the paragraph, which states "Trying to achieve consensus in public consultations, and the consultation process should not be used as a negotiating mechanism with stakeholders" as its arithmetic means was (3.88), and its standard deviation was (0.743), while the paragraph, which states "We should consult all 
relevant target groups" had the lowest approval grades; as its arithmetic mean was (3.13) and its standard deviation was $(0.821)$.

Overall, the general average of the arithmetic means for the answers of the respondents is equivalent to (3.49) and the standard deviation is equivalent to (0.791), which indicates the approval of the respondents upon the scale of these paragraphs was medium, and that their attitudes were positive.

Table 7. Arithmetic means and standard deviations for the members of the study sample answers towards the consultation variable

\begin{tabular}{clcccc}
\hline NO & \multicolumn{1}{c}{ Statement } & A M & S D & Rank & Grade \\
\hline 31 & $\begin{array}{l}\text { Trying to achieve consensus in public consultations, and the } \\
\text { consultation process should not be used as a negotiating } \\
\text { mechanism with stakeholders }\end{array}$ & 3.88 & 0.743 & 1 & High \\
32 & $\begin{array}{l}\text { We should provide clear, concise, and comprehensive } \\
\text { consultation documents for all necessary information }\end{array}$ & 3.32 & 0.811 & 4 & Medium \\
33 & $\begin{array}{l}\text { We should consult all relevant target groups } \\
\text { Ensure sufficient generalization and selection of tools that } \\
\text { adapt to the target groups }\end{array}$ & 3.13 & 0.821 & 5 & Medium \\
35 & $\begin{array}{l}\text { We should identify reactions and feedback individually or } \\
\text { collectively }\end{array}$ & 3.51 & 0.791 & 3 & Medium \\
\hline & General average & 3.49 & 0.791 & - & Medium \\
\hline
\end{tabular}

\subsubsection{Participatory Work}

The participatory work between Civil Society Organizations and Ministry of Political and Parliamentary Affairs in Jordan variable is measured in paragraphs (36-42), as illustrated in table (8), and that the arithmetical means for answers of the study sample that measure the participatory work variable ranged between (3.77- 2.31), and the standard deviations ranged between (0.835- 0.756).

All of these arithmetic means show the approval of the study sample on the paragraphs that measure the participatory work variable, since all the arithmetic means are greater than the default mean.

Also noted that the paragraph, which states "Consultation as a step of the regulatory impact assessment leads to the participatory work of the Ministry of Political and Parliamentary Affairs with civil society organization" as its arithmetic mean was (3.77) and its standard deviation was $(0.761)$, while the paragraph, which states "Defining the problem as a step of the regulatory impact assessment leads to the participatory work of the Ministry of Political and Parliamentary Affairs with civil society organization" had the lowest approval grades; as its arithmetic mean was (2.31) and its standard deviation was (0.835).

Overall, the general average of the arithmetic means for the answers of the respondents is equivalent to (3.18) and the standard deviation is equivalent to (0.799), which indicates the approval of the respondents upon the scale of these paragraphs was medium, and that their attitudes were positive. 
Table 8. Arithmetic means and standard deviations for the members of the study sample answers towards the participatory work variable

\begin{tabular}{|c|c|c|c|c|c|}
\hline NO & Statement & $\mathbf{A M}$ & S D & Rank & Grade \\
\hline 36 & $\begin{array}{l}\text { Application and compliance as a step of the regulatory } \\
\text { impact assessment leads to the participatory work of the } \\
\text { Ministry of Political and Parliamentary Affairs with civil } \\
\text { society organization }\end{array}$ & 3.71 & 0.756 & 2 & High \\
\hline 37 & $\begin{array}{l}\text { Defining the problem as a step of the regulatory impact } \\
\text { assessment leads to the participatory work of the Ministry } \\
\text { of Political and Parliamentary Affairs with civil society } \\
\text { organization }\end{array}$ & 2.31 & 0.835 & 7 & Medium \\
\hline 38 & $\begin{array}{l}\text { Monitoring and evaluation as a step of the regulatory } \\
\text { impact assessment leads to the participatory work of the } \\
\text { Ministry of Political and Parliamentary Affairs with civil } \\
\text { society organization }\end{array}$ & 3.17 & 0.811 & 5 & Medium \\
\hline 39 & $\begin{array}{l}\text { Measuring effects as a step of the regulatory impact } \\
\text { assessment leads to the participatory work of the Ministry } \\
\text { of Political and Parliamentary Affairs with civil society } \\
\text { organization }\end{array}$ & 3.43 & 0.793 & 3 & Medium \\
\hline 40 & $\begin{array}{l}\text { Selecting options as a step of the regulatory impact } \\
\text { assessment leads to the participatory work of the Ministry } \\
\text { of Political and Parliamentary Affairs with civil society } \\
\text { organization }\end{array}$ & 2.67 & 0.843 & 6 & Medium \\
\hline 41 & $\begin{array}{l}\text { Consultation as a step of the regulatory impact assessment } \\
\text { leads to the participatory work of the Ministry of Political } \\
\text { and Parliamentary Affairs with civil society organization }\end{array}$ & 3.77 & 0.761 & 1 & High \\
\hline 42 & $\begin{array}{l}\text { Setting goals as a step of the regulatory impact assessment } \\
\text { leads to the participatory work of the Ministry of Political } \\
\text { and Parliamentary Affairs with civil society organization }\end{array}$ & 3.21 & 0.797 & 4 & Medium \\
\hline & General average & 3.18 & 0.799 & - & Medium \\
\hline
\end{tabular}

\section{Testing the Study Hypotheses}

In order to test the hypotheses of the study, statistical methods were used with the appropriate tests to the nature of the variables and assumptions, using the simple linear regression and the multiple linear regression analysis so as to put the base of acceptances or rejections.

\subsection{Testing the Major Hypothesis}

H0: There will be no statistically significant differences at the level of significance $(\alpha=0.05)$ of the role of regulatory impact assessment (RIA) on the participatory work between Civil Society Organizations and Ministry of Political and Parliamentary Affairs in Jordan.

It is noted from simple regression analysis results described in table (9) that there is an effect of the role of regulatory impact assessment (RIA) on the participatory work between Civil Society Organizations and Ministry of Political and Parliamentary Affairs in Jordan.

This statistically significant effect at the statistically significant level $(\alpha=0.05)$, as the calculated $(\mathrm{T})$ value is (25.12), which is higher than tabulated (T) value, is in line with the simple regression analysis results that explain the $(69.8 \%)$ variance.

According to that the null hypothesis (H0) will be rejected and the alternative hypothesis will be accepted.

Table 9. Testing results of the major hypothesis

\begin{tabular}{ccccc}
\hline Significant $(\mathrm{T})$ & Calculated $(\mathrm{T})$ & Tabulated $(\mathrm{T})$ & (R) Square & $(\mathrm{R})$ \\
\hline 0.001 & 25.12 & 1.960 & 0.667 & 0.786 \\
\hline
\end{tabular}




\subsection{Testing the First Sub-hypothesis}

H01: There will be no statistically significant differences at the level of significance $(\alpha=0.05)$ of the role of defining the problem on the participatory work between Civil Society Organizations and Ministry of Political and Parliamentary Affairs in Jordan.

It is noted from simple regression analysis results described in table (10) that there is an impact of the role of defining the problem on the participatory work between Civil Society Organizations and Ministry of Political and Parliamentary Affairs in Jordan.

This statistically significant effect at the statistically significant level $(\alpha=0.05)$, as the calculated $(\mathrm{T})$ value is (7.841), which is higher than tabulated (T) value, is in line with the simple regression analysis results that explain the $(0.197 \%)$ variance.

According to that the null hypothesis (H01) will be rejected and the alternative hypothesis will be accepted.

Table 10. Testing results of the first sub -hypothesis

\begin{tabular}{ccccc}
\hline Significant $(\mathrm{T})$ & Calculated $(\mathrm{T})$ & Tabulated $(\mathrm{T})$ & $(\mathrm{R})$ Square & $(\mathrm{R})$ \\
\hline 0.000 & 7.841 & 1.960 & 0.197 & 0.444 \\
\hline
\end{tabular}

\subsection{Testing the Second Sub Hypothesis}

H02: There will be no statistically significant differences at the level of significance $(\alpha=0.05)$ of the role of setting goals on the participatory work between Civil Society Organizations and Ministry of Political and Parliamentary Affairs in Jordan.

It is noted from simple regression analysis results described in table (11) that there is a role of setting goals on the participatory work between Civil Society Organizations and Ministry of Political and Parliamentary Affairs in Jordan.

This statistically significant effect at the statistically significant level $(\alpha=0.05)$, as the calculated $(T)$ value is (12.633), which is higher than tabulated $(\mathrm{T})$ value, is in line with the simple regression analysis results that explain the (39.0\%) variance.

According to that the null hypothesis (H02) will be rejected and the alternative hypothesis will be accepted.

Table 11. Testing results of the second sub hypothesis

\begin{tabular}{ccccc}
\hline Significant $(\mathrm{T})$ & Calculated $(\mathrm{T})$ & Tabulated $(\mathrm{T})$ & $(\mathrm{R})$ Square & $(\mathrm{R})$ \\
\hline 0.000 & 12.633 & 1.960 & 0.390 & 0.624 \\
\hline
\end{tabular}

\subsection{Testing the Third Sub-hypothesis}

H03: There will be no statistically significant differences at the level of significance $(\alpha=0.05)$ of the role of selecting options on the participatory work between Civil Society Organizations and Ministry of Political and Parliamentary Affairs in Jordan.

It is noted from simple regression analysis results described in table (12) that there is an impact of selecting options on the participatory work between Civil Society Organizations and Ministry of Political and Parliamentary Affairs in Jordan.

This statistically significant effect at the statistically significant level $(\alpha=0.05)$, as the calculated $(T)$ value is (11.00), which is higher than tabulated $(\mathrm{T})$ value, is in line with the simple regression analysis results that explain the $(32.64 \%)$ variance.

According to that the null hypothesis (H03) will be rejected and the alternative hypothesis will be accepted.

Table 12. Testing results of the third sub -hypothesis

\begin{tabular}{ccccc}
\hline Significant $(\mathrm{T})$ & Calculated $(\mathrm{T})$ & Tabulated $(\mathrm{T})$ & $(\mathrm{R})$ Square & $(\mathrm{R})$ \\
\hline 0.000 & 11.00 & 1.960 & 0.326 & 0.571 \\
\hline
\end{tabular}




\subsection{Testing the Fourth Sub-hypothesis}

H04: There will be no statistically significant differences at the level of significance $(\alpha=0.05)$ of the role of measuring effects on the participatory work between Civil Society Organizations and Ministry of Political and Parliamentary Affairs in Jordan.

It is noted from simple regression analysis results described in table (13) that there is an impact of measuring effects on the participatory work between Civil Society Organizations and Ministry of Political and Parliamentary Affairs in Jordan.

This statistically significant effect at the statistically significant level $(\alpha=0.05)$, as the calculated $(\mathrm{T})$ value is (13.00), which is higher than tabulated (T) value, is in line with the simple regression analysis results that explain the $(33.41 \%)$ variance.

According to that the null hypothesis (H04) will be rejected and the alternative hypothesis will be accepted.

Table 13. Testing results of the fourth sub- hypothesis

\begin{tabular}{ccccc}
\hline Significant $(\mathrm{T})$ & Calculated $(\mathrm{T})$ & Tabulated $(\mathrm{T})$ & $(\mathrm{R})$ Square & $(\mathrm{R})$ \\
\hline 0.002 & 13.00 & 1.960 & 0.356 & 0.534 \\
\hline
\end{tabular}

\subsection{Testing the Fifth Sub-hypothesis}

H05: There will be no statistically significant differences at the level of significance $(\alpha=0.05)$ of the role of application and compliance on the participatory work between Civil Society Organizations and Ministry of Political and Parliamentary Affairs in Jordan.

It is noted from simple regression analysis results described in table (14) that there is an impact of application and compliance on the participatory work between Civil Society Organizations and Ministry of Political and Parliamentary Affairs in Jordan.

This statistically significant effect at the statistically significant level $(\alpha=0.05)$, as the calculated $(\mathrm{T})$ value is (12.32), which is higher than tabulated (T) value, is in line with the simple regression analysis results that explain the $(36.37 \%)$ variance.

According to that the null hypothesis (H05) will be rejected and the alternative hypothesis will be accepted.

Table 14. Testing results of the fifth sub- hypothesis

\begin{tabular}{ccccc}
\hline Significant $(\mathrm{T})$ & Calculated $(\mathrm{T})$ & Tabulated $(\mathrm{T})$ & $(\mathrm{R})$ Square & $(\mathrm{R})$ \\
\hline 0.000 & 12.32 & 1.960 & 0.335 & 0.654 \\
\hline
\end{tabular}

\subsection{Testing the Sixth Sub-hypothesis}

H06: There will be no statistically significant differences at the level of significance $(\alpha=0.05)$ of the role of monitoring and evaluation on the participatory work between Civil Society Organizations and Ministry of Political and Parliamentary Affairs in Jordan.

It is noted from simple regression analysis results described in table (15) that there is an impact of monitoring and evaluation on the participatory work between Civil Society Organizations and Ministry of Political and Parliamentary Affairs in Jordan.

This statistically significant effect at the statistically significant level $(\alpha=0.05)$, as the calculated $(\mathrm{T})$ value is (11.55), which is higher than tabulated $(\mathrm{T})$ value, is in line with the simple regression analysis results that explain the $(31.46 \%)$ variance.

According to that the null hypothesis (H06) will be rejected and the alternative hypothesis will be accepted.

Table 15. Testing results of the sixth sub- hypothesis

\begin{tabular}{ccccc}
\hline Significant $(\mathrm{T})$ & Calculated $(\mathrm{T})$ & Tabulated $(\mathrm{T})$ & $(\mathrm{R})$ Square & $(\mathrm{R})$ \\
\hline 0.001 & 11.55 & 1.960 & 0.432 & 0.671 \\
\hline
\end{tabular}




\subsection{Testing the Seventh Sub-hypothesis}

H07: There will be no statistically significant differences at the level of significance $(\alpha=0.05)$ of the role of consultation on the participatory work between Civil Society Organizations and Ministry of Political and Parliamentary Affairs in Jordan.

It is noted from simple regression analysis results described in table (16) that there is an impact of consultation on the participatory work between Civil Society Organizations and Ministry of Political and Parliamentary Affairs in Jordan.

This statistically significant effect at the statistically significant level $(\alpha=0.05)$, as the calculated $(\mathrm{T})$ value is (12.85), which is higher than tabulated $(\mathrm{T})$ value, is in line with the simple regression analysis results that explain the $(39.12 \%)$ variance.

According to that the null hypothesis (H07) will be rejected and the alternative hypothesis will be accepted.

Table 16. Testing results of the seventh sub- hypothesis

\begin{tabular}{ccccc}
\hline Significant $(\mathrm{T})$ & Calculated $(\mathrm{T})$ & Tabulated $(\mathrm{T})$ & (R) Square & $(\mathrm{R})$ \\
\hline 0.000 & 12.85 & 1.960 & 0.366 & 0.775 \\
\hline
\end{tabular}

\section{Recommendations}

Based on the results of the study, and by testing its hypotheses, the researcher recommends the following:

1) Emphasizing on-going consultations between the Ministry of Political and Parliamentary Affairs and the civil society organizations to ensure the consolidation of participatory work.

2) Emphasizing the implementation of the steps of the regulatory impact assessment (RIA) in partnership between the Ministry of Political and Parliamentary Affairs and the civil society organizations.

3) Identifying the preferred option for participatory work between the Ministry of Political and Parliamentary Affairs and the civil society organizations to improve policy-making.

4) Conducting further researches on the impact of regulatory impact assessment (RIA) outcomes on the participatory work between the Ministry of Political and Parliamentary Affairs and the civil society organizations.

\section{References}

Adelle, C., Macrae, D., Marusic, A., \& Naru, F. (2015). New development: Regulatory impact assessment in developing countries - tales from the road to good governance. Public Money \& Management, 35(3), 233-238. https://doi.org/10.1080/09540962.2015.1027500

Aladwan, K. I., \& Aldab, K. M. (2015). The Jordanian Parliamentary Institution: A Study in Political Representation. Dirrasat Journal, 42(1).

Barreto, R., Cordova, C., \& Gutan, I. (2015). A Model for a Regulatory Impact Analysis System in Tajikistan. ADB BRIEFS NO. 51.

Carothers, T., \& Ottaway, M. (Eds.). (2010). Uncharted journey: promoting democracy in the Middle East. Carnegie Endowment.

Dağdeviren, M. (2008). Decision making in equipment selection: an integrated approach with AHP and PROMETHEE. Journal of Intelligent Manufacturing, 19(4), 397-406. https://doi.org/10.1007/s10845-008-0091-7

Ivana Rosenzweigová. (2016). Policy Papers on Cooperation between the State and Civil Society Organizations. A Comparative Analysis, Bishkek, P 43.

Kasamets, A. (2001). Impact Assessment of Legislation for Parliament and Civil Society: a Comparative Study. Legal and Regulatory Impact Assessments of Legislation (47-96). Talin: ECPRD.

Misztal, B. (2013). Trust in modern societies: The search for the bases of social order. John Wiley \& Sons.

MOPPA. (2017). Objectives of the general strategy of the ministry. Retrieved from http://www.moppa.gov.jo/Pages/viewpage.aspx?pageID=123

Radaelli, C. (2002, March). The politics of regulatory impact analysis in the OECD countries: best practice and 
lesson-drawing. In Workshop On Regulatory Impact Analysis In Comparative Perspective, London (Vol. 11).

Skopje, M. (2015). Public participation: government of the people, by the people, for the people, Center for Research and Policy Making.

Wiktorowicz, Q. (2000). Civil society as social control: State power in Jordan. Comparative politics, 43-61. https://doi.org/10.2307/422423

Yom, S. (2005). Civil society and democratization in the Arab world. Middle East, 9(4), 15-32.

\section{Copyrights}

Copyright for this article is retained by the author(s), with first publication rights granted to the journal.

This is an open-access article distributed under the terms and conditions of the Creative Commons Attribution license (http://creativecommons.org/licenses/by/4.0/). 